\title{
Sampling of organic volatiles in the atmosphere at moderate and low pollution levels
}

\author{
J RUDOLPH, K.P MÜLLER and R KOPPMANN *
}

\begin{abstract}
Several techniques are avalable for measuning organic volatiles in the atmosphere. For measurements at low and moderate pollution levels (between several $\mu \mathrm{g} \mathrm{m}^{-3}$ and a fraction of a $\mu \mathrm{g} \mathrm{m}^{-3}$ ), the existing methods can be adopted to a broad range of different compounds. Whole-air sampling in stainless-steel containers with metal bellows valves combined with subsequent gas chromatographic separation after preconcentration in the laboratory is probably the best procedure for low and medium molecular weight trace gases of moderate or low polarity and reasonable chemical stability (e.g., hydrocarbons and halocarbons). For organic compounds of lower volatility, adsorptive sampling on non-polar porous organic polymers (e.g. Tenax) and thermal desorption combined with cryotrapping and gas chromatographic separation of the sampled compounds is widely used However, there are often substantial problems due to artefact formation or loss reactions Owing to the generally larger sample volumes, these problems are even more pronounced for sorptive sampling technques combined with sample recovery by solvent extraction. Unfortunately, the general understanding of the various processes of sample degradation due to chemical reactions of reactive components of the atmosphere with each other or with the sorbent is not yet sufficient to allow reasonable estimates of the extent of such interferences without elaborate test procedures.
\end{abstract}

Keywords. Air, Sampling procedures; Extraction, Organic volatıles

The demand for accurate, reliable and sensitive techniques for the monitoring of organic trace constituents in the atmosphere has increased tremendously in the recent past. The reasons include not only a growing concern for the quality of the environment but also the realization that atmosphenc pollution is not only a local problem. At the same time, the number of different organic compounds which are emitted into the atmosphere has been rising steadily. Further, it has been recognized that several substances which had been considered harmless can pose serious hazards to the environment. There is a broad range of techniques for the determination of organic compounds at trace levels which are sufficiently sensitive and selective. Chromatography (predominantly LC and GC) is the most widely used method and allows the identification and quantification of organic compounds in sub-nanogram amounts. With few exceptions, the analysis itself is carried out in the laboratory, which means that the sample has somehow to be transported to the laboratory. For many kinds of environmental measurements, representative and contamination- or lossfree sampling often requires substantial efforts and in general air is one of the most difficult environmenal media for sampling. The problems are easy to understand but difficult to solve. Sample containers for air are not only more complicated than those for solid or liquid material but also, owing to the low density of air, the volume which has to be collected for an analysis for trace components is generally larger than that for solidor liquid-phase samples. Owing to the low density 
of air, contamination effects or wall losses have a greater impact on the concentration of the trace constituents. For example, contamination of a 1$\mathrm{dm}^{3}$ sample by $1 \mu \mathrm{g}$ of substance changes the concentration of a liquid sample by $10^{-9} \mathrm{~g} \mathrm{~g}^{-1}$ but for an air sample by nearly $10^{-6} \mathrm{~g} \mathrm{~g}^{-1}$.

There are several ways to circumvent or reduce these problems, ranging from the collection of air samples at high pressure to preconcentration steps combined with the sampling procedure. However, these require more or less complicated procedures in the field instead of the laboratory. If one excludes the few exceptions where it is worthwhile (or necessary) to instal a complete laboratory or at least a dedicated measuring instrument in the field, these sampling steps are in general performed under less favourable and controlled conditions than in the laboratory. This again increases the problem of sample integrity. Consequently, for air analysis the sampling procedure is of even more importance as a key step to reliable measurements than for most other environmental media.

In this paper the more widely used sampling techniques are discussed and some examples of their application are briefly presented. The main focus is on measurement techniques which are used for low or moderate pollution levels since a number of problems and uncertainties still exist.

\section{THE ANALYTICAL PROBLEM}

Together with the two main components of air, nitrogen and oxygen, the noble gases, water vapour and carbon dioxide account for more than $99.99 \%$ of the atmosphere. The remaining fraction consists of a large number of components, some of them present at levels of $\mathrm{mg} \mathrm{m}^{-3}$ or fractions thereof (e.g., $\mathrm{CH}_{4}, \mathrm{CO}, \mathrm{H}_{2}, \mathrm{~N}_{2} \mathrm{O}$ ). However, most of the atmospheric trace gases are in the $\mu \mathrm{g} \mathrm{m}^{-3}$ range and below. With very few exceptions (e.g., NO, $\mathrm{NO}_{2}, \mathrm{O}_{3}, \mathrm{SO}_{3}$ ) they are organic compounds. The number of different organic trace constituents in the atmosphere is very large and the physicochemical and chemical properties of the various compounds differ. Moreover, as a result of the non-uniform distribution of their vanous sources (e.g., engine exhaust, fuel and solvent evaporation, natural gas losses, emissions from chemical factories, vegetation emissions, waste incineration) and their different atmospheric residence times (mostly between several hours and several weeks), both the absolute concentrations and the relative patterns in the atmosphere can change drastically with time and location. The atmosphere also contains several oxidizing trace gases as ozone, peroxides and nitrogen dioxide at low but still significant levels. These might react with container walls, sorbents or the collected organic trace gases during sampling and storage. This can cause the formation of artefacts or losses of sample, especially if these oxıdizing trace components are precontracted together with the sample.

The only major component which cannot be easily separated from the organic trace gases is water vapour. Depending on temperature and relative humidity, the atmospheric content of gaseous water may reach several percent. This exceeds the concentrations of most organic trace gases by six or more orders of magnitude. In this context, it should be mentioned that for atmospheric measurements of high accuracy it has become customary to give concentrations (or mixing ratios) based on the amount of dry (water vapour-free) air in order to eliminate the dilution effect which might be caused by the varying content of atmopheric water vapour. No general procedure for the collection of representative and stable samples for organic compoundes in air exists, but each procedure has to be adopted to the kind of organic substances, the expected concentration range and interfering substances possibly present.

However, there is another restriction which has to be considered in order to select or design a sampling procedure for organic trace gases in the atmosphere. As the sampling locations or platforms (e.g., ships, airplanes) are selected primarily on the basis of the given monitoring task, the selected sampling site often offers no or only restricted logistic support such as housing for the sampling equipment and electrical power. Also, not every suitable sampling site is easily accessible with heavy equipment. Finally, one has to consider the desired sampling frequency and integration time for the sampling and also the total 
number of samples if one wants to select the optimum sampling technique.

\section{WHOLE-AIR SAMPLING}

In spite of the various problems mentioned above, the collection of air samples without any preconcentration or fractionation has been applied successfully for measurements of trace components in the atmosphere [1-7]. Owing to possible adsorptive losses on the walls of the sample containers, whole-air sampling is in general not applicable for measurements of compounds of low volatility or high polarity (e.g., alcohols, carboxylic acıds, polyaromatic hydrocarbons). Whole-air sampling is most widely used for measurements of low and medium molecular weight hydrocarbons and light halocarbons (e.g., chlorofluorocarbons, tetrachloromethane, tri- and tetrachloroethene). Especially for measurements where high accuracy and reproducibility are needed, whole-air sampling is often applied as it eliminates uncertainties which can be caused by variations of sampling efficiency or the uncertainties in the determination of the sample volume in the field. For stable organic compounds of high volatility, measurements with a relative standard deviation of a few percent or sometimes less than $1 \%$ at concentration levels below $1 \mu \mathrm{g} \mathrm{m}^{-3}$ are possible [4,5,7]. A listing of some applications of whole-air sampling is given in Table 1. The samples are analyzed later by GC in combination with a preconcentration step at low temperatures, sometimes also by direct injection of a few $\mathrm{cm}^{3}$ without preconcentration.

The most widely used sampling vessels are plastic bags (often Teflon, Tedlar or aluminized Tedlar) and glass or stainless-steel containers [119]. Polymer bags are probably the least expensive sample containers but in general the contamination levels due to outgassing of the container material are substantial. The use of certain types of polymer bags and its limitations have been evaluated by Seila et al. [20]. These bags are only useful for measurements in strongly polluted air or for otherwise relatively high trace gas concentrations in the range of several $\mu \mathrm{g} \mathrm{m}^{-3}$ and more. Under these conditions reasonable results can be obtained. In order to fill polymer bags the air has to be pumped into the bag. This adds another potential source of sample deterioration, although the possible contamination risk can be

TABLE 1

Examples of measurements of organic volatiles by whole-air collection

\begin{tabular}{|c|c|c|c|c|}
\hline $\begin{array}{l}\text { Type of sample } \\
\text { contaner }\end{array}$ & Sampling procedure & Analysed compounds & $\begin{array}{l}\text { Concentration } \\
\text { range }\left(\mu \mathrm{g} \mathrm{m}^{-3}\right)\end{array}$ & Ref \\
\hline Teflon bags & Filled by pumping & $\mathrm{C}_{2}-\mathrm{C}_{6}$ hydrocarbons & $0.5-50$ & 8,11 \\
\hline Tedlar bags & Filled by pumping & Several $C_{2}-C_{10}$ hydrocarbons & $0.5-200$ & $9,10,12,13$ \\
\hline Tedlar bags & Filled by pumping & Isoprene & $0.1-15$ & 6 \\
\hline $\begin{array}{l}\text { Glass flasks with } \\
\text { Teflon stopcocks }\end{array}$ & $\begin{array}{l}\text { Air sample drawn } \\
\text { through flask by manual } \\
\text { pumping with rubber bulb }\end{array}$ & $\mathrm{C}_{1}-\mathrm{C}_{6}$ hydrocarbons & $0.5-50$ & 24 \\
\hline $\begin{array}{l}\text { Glass flasks with } \\
\text { Teflon stopcocks }\end{array}$ & $\begin{array}{l}\text { Pressurized with metal } \\
\text { bellows pump }\end{array}$ & Isoprene, $C_{2}$ hydrocarbons & $005-3$ & 25 \\
\hline $\begin{array}{l}\text { Stainless-steel flasks } \\
\text { with metal bellows } \\
\text { valves }\end{array}$ & Grab & $\mathrm{C}_{2}-\mathrm{C}_{6}$ hydrocarbons & $0.03-10$ & $1,4,31$ \\
\hline As above & & $\mathrm{C}_{2}-\mathrm{C}_{10}$ hydrocarbons & $0.05-3$ & 2 \\
\hline $\begin{array}{l}\text { As above } \\
\text { As above }\end{array}$ & $\begin{array}{l}\text { Pressunzed with metal } \\
\text { bellow pump }\end{array}$ & $\begin{array}{l}\mathrm{C}_{2}-\mathrm{C}_{3} \text { hydrocarbons and some } \\
\text { halocarbons, benzene, toluene }\end{array}$ & $002-3$ & 16 \\
\hline As above & $\begin{array}{l}\text { Pressurized with metal } \\
\text { bellows pump }\end{array}$ & Benzene, toluene & $0.03-3$ & 17 \\
\hline As above & Indurectly pressurzed & $\mathrm{C}_{2}-\mathrm{C}_{5}$ hydrocarbons & $0.01-3$ & 19 \\
\hline As above & $\begin{array}{l}\text { Cryogenic freeze-out } \\
\text { (liquJd Ne) }\end{array}$ & Chlorofluoromethanes & $0.001-1$ & 33 \\
\hline
\end{tabular}


reduced if Teflon-lined pumps or metal bellows pumps are used. The problem of sample contamination by pumps has been elıminated by putting the polymer bag in a rigid cylınder and filling the bag by drawing the air out of the cylinder [8]. However, this reduces some of the advantages of polymer bags for air sample collection (low weight, inexpensive, small volume before sampling). The sample volume for polymer bags range from ca. 1 $\mathrm{dm}^{3}$ to several tens of $\mathrm{dm}^{3}$.

Glass or stainless-steel sample containers cause less contamination problems but are more expensive than plastic bags. In the past, glass vessels have been widely used for air sampling [21-26], but more recently mostly stainless-steel canisters have become more popular $[1-5,7,14,17,27-39]$. Stainless-steel sample canisters are nowadays in general equipped with metal bellows valves [1$5,14,16,19,28,29]$, which avoids all polymeric seals etc. This minimizes possible contamination effects. It has been shown that even extremely small pieces of polymers used in valves can cause contamination at sub- $\mu \mathrm{g} \mathrm{m}^{-3}$ levels [5]. Vacuum-tight glass valves usually contain polymeric seals or packıngs and therefore glass containers are less suitable for measurements of $\mu \mathrm{g} \mathrm{m}^{-3}$ or sub $\mu \mathrm{g}$ $\mathrm{m}^{-3}$ concentrations of organic trace gases [24]. Carefully pretreated and conditioned stainlesssteel containers can be used for measurements of sub- $\mu \mathrm{g} \mathrm{m}^{-3}$ levels of many low and medium molecular weight hydrocarbons and halocarbons without any significant interference due to contamination or surface losses [1-5,16-19]. In addition to thorough cleaning of the sample containers, minumization of the active surface area is essential. Electropolishing of the internal surfaces and electron-beam vacuum welding of all connections are examples of techniques that help to optimize the performance of stainless-steel sample containers [14,31]. There is not yet a "standard" procedure for preparing, conditioning and cleaning such containers. The cleaning is done either by flushing the canisters with a high-purity gas (e.g., $\mathrm{He}$ or $\mathrm{N}_{2}$ ) or by evacuation with a high-vacuum pump $10^{-3}-10^{-5} \mathrm{~Pa}$ residual pressure). Conditioning sometimes is done by heating to $400-600$ $\mathrm{K}$, exposure to moist air or oxygen at elevated temperatures or simply by flushing with ambient air. It is essential to check the sample canisters thoroughly for contamination effects and sample stability if the concentrations of the organic trace gases are in the lower $\mu \mathrm{g} \mathrm{m}^{-3}$ or $\mathrm{ng} \mathrm{m}^{-3}$ range, as their performance depends stronlgy on a number of details which are difficult to control. Still, for sub- $\mu \mathrm{g} \mathrm{m}^{-3}$ levels of light halocarbons and hydrocarbons, stainless-steel containers with metal bellows valves are probably the most reliable and general sampling equipment.

There are two significant disadvantages. These sample containers are fairly expensive and the preparation of the canisters is elaborate, requires expensive equipment such as turbomolecular vacuum pumps and has to be done very thoroughly to obtam reliable results. The sampling procedure itself can be very simple. The evacuated container is taken into the field and the sample is collected by opening the valve of the container ("grab" sampling). If containers with two valves are used, they can be flushed with ambient air prior to sampling. If the air is pulled through the sample container, sample deterioration due to the pump is avoided. This procedure allows the surface of the sample container to equilibrate with the ambient air prior to sample collection and removes contamination in the container which might be caused by leakıng valves or outgassing of the internal surfaces.

In both instances the collected sample is at ambient pressure. In order to remove the air from the container in the laboratory for analysis, either a vacuum system is needed or the samples have to be pressurized with a clean, inert gas $\left(\mathrm{He}, \mathrm{N}_{2}\right)$. As the volume of the sample containers is, for practical reasons, limited to a few $\mathrm{dm}^{3}$, the total amount of air which is available for analysis is limited to a few grams. Larger amounts of air can be collected by pressurizing the samples. This is done by pumping $[7,14-17,30,32]$ or cryogenically $[33,34]$. The use of pumps adds another source of sample deterioration, and even for metal bellows pumps contamination is possible for some trace gases [32]. Cryogenic sampling is done by reducing the temperature of the sample contaner below the condensation temperature of air, e.g., by immersing the container in liquid nitrogen or neon. The sampled air can be transferred to the laboratory 
TABLE 2

Specific retention volumes at $303 \mathrm{~K}$ [52]

\begin{tabular}{|c|c|c|c|c|c|c|c|}
\hline \multirow[t]{2}{*}{ Adsorbate } & \multirow{2}{*}{$\begin{array}{l}\text { Boilıng } \\
\text { point (K) }\end{array}$} & \multicolumn{6}{|c|}{ Specific retention volume $\left(\mathrm{dm}^{3} \mathrm{~g}^{-1}\right)$} \\
\hline & & $\begin{array}{l}\text { Tenax } G C \\
\left(13-30 \mathrm{~m}^{2} \mathrm{~g}^{-1}\right)\end{array}$ & $\begin{array}{l}\text { Porapak Q } \\
\left(100-200 \mathrm{~m}^{2} \mathrm{~g}^{-1}\right)\end{array}$ & $\begin{array}{l}\text { Molecular } \\
\text { sieve 13X }\end{array}$ & $\begin{array}{l}\text { Porous } \\
\text { Alumina } \\
\left(300 \mathrm{~m}^{2} \mathrm{~g}^{-1}\right)\end{array}$ & $\begin{array}{l}\text { Carbopack B } \\
\left(100 \mathrm{~m}^{2} \mathrm{~g}^{-1}\right)\end{array}$ & $\begin{array}{l}\text { Carbopack C } \\
\left(12 \mathrm{~m}^{2} \mathrm{~g}^{-1}\right)\end{array}$ \\
\hline Acetaldehyde & 294 & 0.24 & 0.5 & $>5000$ & & 0.02 & 0 \\
\hline n-Propylamine & 320.8 & 2.2 & & $>5000$ & 3.7 & 078 & 0.03 \\
\hline n-Hexane & 341.7 & 92 & 24 & 670 & 56 & 220 & 1.0 \\
\hline Ethanol & 351.4 & 0.41 & 1.2 & $>12000$ & 17 & 0.06 & 0 \\
\hline Cyclohexane & 353.7 & 97 & 25 & 220 & 24 & 11 & 0.13 \\
\hline Cyclohexene & 356 & 13 & 27 & & 9.1 & 18 & 0.26 \\
\hline Tnchloroethene & 360 & 15 & 25 & $>5000$ & 25 & 14 & 042 \\
\hline n-Butanol & 373 & 58 & 13 & 260 & 0.12 & 18 & 008 \\
\hline 1,4-Dioxane & 374 & 25 & 31 & $>13000$ & 50 & 23 & 012 \\
\hline Pyridine & 388.5 & 29 & 29 & $>13000$ & 100 & 16 & 0.41 \\
\hline Chlorobenzene & 404.7 & 93 & 190 & $>20000$ & 260 & 480 & 4.3 \\
\hline$p$-Xylene & 411 & 190 & 420 & $>20000$ & 760 & 4500 & 39 \\
\hline$\alpha$-Pinene & 429 & 20 & 1600 & $>20000$ & & 1300 & 3.5 \\
\hline Aniline & 4574 & 360 & 970 & $>20000$ & 2900 & 210 & 5.2 \\
\hline Naphthalene & 4911 & 1500 & 21000 & $>20000$ & 9200 & 33000 & 1000 \\
\hline $\begin{array}{l}\text { Pentachloro- } \\
\text { phenol }\end{array}$ & 583 & 78000 & $2 \times 10^{6}$ & $>20000$ & $10^{6}$ & $10^{7}$ & 43000 \\
\hline
\end{tabular}

either in the condensed state or at ambient temperature under pressure. The problem with cryogenic "freeze-out" sampling is the high concentrations of oxidizing atmospheric constituents such as ozone, oxides of nitrogen or peroxides in the condensed phase. Thus losses of organic compounds which are easily oxidized can occur, e.g., alkenes may be partly removed by reaction with ozone. Both means of collecting pressurized samples need additional equipment in the field. The sample pressure can be as high as 10-20 atm and thus large amounts of air are available for analysis in the laboratory. Owing to the increased amount of sample, contamination effects or adsorptive losses are reduced.

A final possibility is the use of gas-tight syringes for air sampling $[26,35]$. They might be useful for special cases such as sampling of air with high concentrations of organic trace compounds, but owing to the generally high contamination effects and their limited leak tightness, their use for air sampling cannot be recommended.

\section{ADSORPTIVE SAMPLING}

Basically there are two different ways to concentrate volatile organic compounds from the atmosphere on a sorbent. For so-called passive sampling the adsorbent is exposed in a defined way to the atmosphere and the adsorption process is controlled by the adsorption properties of the sorbent and diffusion processes ("diffusion tubes"). The main application of passive samplers is monitoring of workplace atmospheres, dosimetry and the control of industrial areas with potentially very high pollution levels. The other possibility, active sampling, is to pump a defined volume of air through a sorption tube (a short piece of tubing packed with the adsorbent). Theoretically, active sampling can be treated as frontal chromatography and the sampling efficiencies can be estimated from the retention data of the adsorbent. In Table 2 the specific retention volumes of some organic volatiles on several adsorbents are given. In general, active sampling is more adequate than passive sampling for measurements of air with average or low pollution levels. As ad- 
TABLE 3

Examples of adsorptive sampling of organic volatıles in air

\begin{tabular}{|c|c|c|c|c|c|c|c|c|c|}
\hline Adsorbent & Length (mm) & I.d. (mm) & Material & $\begin{array}{l}\text { Sampling } \\
\text { tume (mun) }\end{array}$ & $\begin{array}{l}\text { Sampled } \\
\text { volume }\left(\mathrm{dm}^{3}\right)\end{array}$ & $\begin{array}{l}\text { Analysed } \\
\text { compounds }\end{array}$ & $\begin{array}{l}\text { Concentration } \\
\text { range }\left(\mu \mathrm{g} \mathrm{m}{ }^{-3}\right)\end{array}$ & $\begin{array}{l}\text { Sample } \\
\text { analysis }\end{array}$ & Ref. \\
\hline Tenax TA & 250 & 4 & Glass & $10-60$ & $1-20$ & $\begin{array}{l}\mathrm{C}_{2}-\mathrm{C}_{4} \text { halo- } \\
\text { carbons }\end{array}$ & $0001-0.5$ & $\begin{array}{l}\text { Thermal } \\
\text { desorption, } \\
\text { GC-ECD }\end{array}$ & $39-41$ \\
\hline Tenax TA & 170 & 4.5 & Glass & $10-40$ & $1-6$ & $\begin{array}{l}\mathrm{C}_{6}-\mathrm{C}_{9} \text { hydro- } \\
\text { carbons, some } \\
\text { halocarbons }\end{array}$ & $0.05-50$ & $\begin{array}{l}\text { Thermal } \\
\text { desorption, } \\
\text { GC-MS }\end{array}$ & 51 \\
\hline Tenax GC & 200 & 2 & $\begin{array}{l}\text { Glass, } \\
\text { stainless } \\
\text { steel }\end{array}$ & & $1-1.5$ & $\begin{array}{l}\text { Selected } \\
\text { monoterpenes }\end{array}$ & $0.03-1$ & $\begin{array}{l}\text { Thermal } \\
\text { desorption, } \\
\text { GC-MS } \\
\text { GC-FID }\end{array}$ & 41,46 \\
\hline $\begin{array}{l}\text { Tenax GC, } \\
\text { Carbopack BHT, } \\
\text { Ambersorb XE-340 }\end{array}$ & 110 & $8(o d)$. & Glass & -100 & $3-30$ & $\begin{array}{l}\mathrm{C}_{5}-\mathrm{C}_{14} \text { hydro- } \\
\text { carbons, alde- } \\
\text { hydes, ketones, } \\
\text { esters, ethers, } \\
\text { halocarbons }\end{array}$ & $05-100$ & $\begin{array}{l}\text { Thermal } \\
\text { desorption, } \\
\text { GC-MS }\end{array}$ & 44 \\
\hline Tenax GC & 200 & 2 & $\begin{array}{l}\text { Stainless } \\
\text { steel }\end{array}$ & $1-5$ & $11-1.4$ & $\begin{array}{l}\text { Benzene, } \\
\text { toluene, } C_{2} \\
\text { alkylbenzenes }\end{array}$ & $0.01-1$ & $\begin{array}{l}\text { Thermal } \\
\text { desorption, } \\
\text { GC-FID }\end{array}$ & 40 \\
\hline $\begin{array}{l}\text { Porous alumina } \\
\text { at dry-ice } \\
\text { temperature }\end{array}$ & & & & 30 & 1.6 & $\begin{array}{l}\mathrm{C}_{2}-\mathrm{C}_{5} \text { hydro- } \\
\text { carbons }\end{array}$ & $1-200$ & $\begin{array}{l}\text { Thermal } \\
\text { desorption, } \\
\text { GC-FID }\end{array}$ & 50 \\
\hline $\begin{array}{l}\text { Active } \\
\text { charcoal }\end{array}$ & $\begin{array}{c}\text { S-mg } \\
\text { traps }\end{array}$ & & & $30 / 1000$ & $12 / 300$ & $\begin{array}{l}\text { Alkyl } \\
\text { nitrates }\end{array}$ & $001-0.2$ & $\begin{array}{l}\text { Extraction, } \\
\text { GC-MS }\end{array}$ & 73 \\
\hline $\begin{array}{l}\text { Porous glass } \\
\text { beads and } \\
\text { Amberlite } \\
\text { XAD-2 }\end{array}$ & & & & $\begin{array}{l}1500- \\
7500\end{array}$ & $\begin{array}{l}15000- \\
75000\end{array}$ & $\begin{array}{l}\text { Polychlori- } \\
\text { nated bi- } \\
\text { phenyls }\end{array}$ & $00005-001$ & $\begin{array}{l}\text { Extraction, } \\
\text { GC-ECD }\end{array}$ & 74 \\
\hline
\end{tabular}


sorptive sampling procedures only collect a more or less well defined fraction of all the different atmospheric constituents, sorptive sampling is always combined with a preconcentration step. Provided that there are no other components which interfere with the preconcentration procedure, the highest possible sampling volume is essentially identical with the breakthrough volume of the analyte with the lowest breakthrough volume. The necessary sample volume is given by the detection limit desired and the sensitivity of the subsequence chromatographic analysis.

Ideally the sampling should be as selective as possible and only the compounds which have to be analysed should be enriched. In reality the selectivity of the sampling step is considered sufficient if there is no significant adsorption of the main atmospheric components; nitrogen, oxygen, water vapour and carbon dioxide. The separation between the various trace constituents is part of the subsequent chromatographic analysis.

For this analysis the sample has to be recovered from the adsorbent. The sample is usually thermally desorbed in an inert gas stream or extracted with a solvent. Thermal desorption is combined with GC separation and detection, whereas liquid-liquid extraction results in a sample that can be analysed by almost all techniques for the measurement of organic trace components in solvents. There are four possible combinations; passive sampling with liquid-liquid extraction, active sampling with liquid-liquid extraction, passive sampling with thermal desorption and active sampling with thermal desorption. For each of these combinations many different adsorbents can be used and there are numerous possible sampling and desorption conditions plus a variety of different technical solutions of the problems encounted during field sampling. The following sections are restricted to those procedures which have been more widely used for atmospheric sampling or look most promising.

\section{Thermal desorption}

Adsorptive sampling in combination with thermal desorption and subsequent GC analysis has been frequently applied for measuring of organic volatiles in the atmosphere [36-51]. Although there are a large number of different techniques the most widely used procedures can be summarized as follows.

Several $\mathrm{dm}^{3}$ of air are pumped (usually with the pump downstream of the adsorbent to avoid sample degradation due to the pump) through a small tube (glass, stainless steel) several to a few tens of centimetres length and a few millimetres i.d. packed with the adsorbent. Often Tenax and similar non-polar organic porous polymers are used. The sampling temperature is generally around 300 $\mathbf{K}$ (ambient temperature). After sampling the tubes are closed to prevent contamination during transfer to the laboratory. In the laboratory the sampling tubes are heated to ca. 500-550 $\mathrm{K}$ and simultaneously an inert gas of high purity is passed through the adsorption column. The flow direction during desorption is reversed; flow-rates range from a few to several tens of $\mathrm{cm}^{3} \mathrm{~min}^{-1}$. The desorption time is generally $10-30 \mathrm{~min}$. The desorbed sample is focussed either in a cryotrap prior to injection onto the separation column or on the separation column itself at reduced temperatures.

These types of procedures are widely used, fairly easy to operate in the field, allow limits of detection of $<1 \mu \mathrm{g} \mathrm{m}^{-3}$ and can also be used in combination with high-resolution capillary columns. Applications range from small, portable, battery-powered instruments to automated sampling devices which allow time series measurements with several independently collected samples. Compounds with boiling points in the range from $340 \mathrm{~K}\left(\mathrm{C}_{6}\right.$ hydrocarbons $)$ to $600 \mathrm{~K}\left(\mathrm{C}_{19}\right.$ alkanes) can be sampled. Non-polar adsorbents are used to avoid the collection of water vapour which would increase the size of the adsorbed sample and affect the sampling efficiency owing to the reduction of the available surface area of the adsorbent. Consequently, the sampling efficiencies for smaller organic molecules with polar functional groups (e.g., alcohols or amines) are often very low. There are numerous adsorbents which are more efficient for polar compounds (see, e.g., Table 3) but, apart from the problem that these polar adsorbents retain substantial amounts of water from the atmosphere, their performance with respect to recovery efficiencies by thermal desorp- 
tion and blank values is sometimes poor. In some studies solid sorbents were used at subambient temperatures to collect very volatile organic trace gases from air [47-49], but the increased instrumental and logistic efforts with subambient-temperature sampling and storage of the collected samples have prevented the wider use of such procedures. Further, the possible condensation of water vapour at reduced temperatures limits the sample volume or requires the use of a drying agent. However, it should be mentioned that preconcentration at subambient temperatures is widely used for the analysis of whole-air samples in the laboratory $[1-5,16-19,28-32]$ or for in situ analysis [53].

For compounds of high volatility the applicability of adsorptive sampling is limited by the breakthrough volume of the compound in the trap, whereas for very low-boiling and strongly adsorbed compounds sample recovery is the limiting step. The thermal stability of both the adsorbent and the adsorbate limit the maximum temperatures for the thermal desorption process and thus reduces the recovery efficiency for compounds of very low volatility [54]. The use of combinations of different adsorbents in series can increase the range of organic volatiles which might be determined by adsorption-thermal desorption techniques [55], but the problem of artefact formation increases with the number of different adsorbents used. The main problem which limits the applicability of adsorptive sampling is the formation of artefacts and losses by various mechanisms [41,56-66]. Apart from the formation of artefacts during sample desorption by thermal decay of the sorbent, the main source of sample degradation are the reaction of reactive adsorbed compounds with each other, exther during sampling or during storage, the reaction of adsorbed organic compounds with reactive trace species in the gas phase, e.g., ozone or nitrogen dioxide, and the thermal decay of sampled compounds during desorption. These processes can cause both artefact formation or losses. Another possiblity is the formation of artefacts from the reaction of oxidizing atmospheric trace constituents such as ozone, hydrogen peroxide, nitric acid or nitrogen dioxide with the adsorbent. As all these possible sources of sample degradation depend strongly on the type of adsorbent, its preconditioning, the sampling conditions (temperature, sample volume, loading of adsorbent with sample) and the composition of the atmosphere, e.g., ozone concentration [56-58], it is difficult to generalize the limitations caused by these problems. Nevertheless, it is possible to establish a few rough guidelines. Losses primarily occur for compounds which are easily oxidized, e.g., by ozone, such as dienes. These losses can be reduced by minimizing the sample volume and the sampling time [41]. Artefacts are primarily oxygenated hydrocarbons (aldehydes, ketones, etc.), but to some extent the formation of aromatic and halogenated hydrocarbons has also been observed $[56,58]$.

These effects can be reduced by preconditioning the adsorbent and sometimes they decrease with increasing numbers of samples collected with the same adsorption trap [56]. In addition to the conventional laboratory tests of breakthrough volume, sampling and recovery efficiency, blank levels for unexposed samples and reprodubility for parallel samples, the so-called "distributed volume sampling" can be very helpful in identifying problems $[56,67]$. This technique is based on the assumption that the interfering processes are not directly proportional to the sample volume. In this instance the extents of the interferences differ in samples collected simultaneously but with different flow-rates.

Finally there is the possibility of removing the interfering species by chemical reactions or adsorption processes on a "precolumn" prior to sample collection itself. These so-called "reaction-sorption" methods are generally applied to measurements at extremely high pollution levels [68], but for average or low levels of pollution the additional risks of artefact formation, adsorptive losses, memory effects, etc., exceed the possibly advantages. Apart from chemicals to remove carbon dioxide or water vapour from the sampled air, no successful applications of such techniques for low pollution levels have been reported.

Sample recovery by liquid-liquid extraction

Instead of thermal desorption of the collected sample, the adsorbed organic compounds can also 
be recovered by liquid-liquid extraction of the adsorbent. In principle the same types of adsorbents can be used as for thermal desorption, with one significant difference. Owing to the limited maximum temperatures for thermal desorption, the recovery of strongly sorbed compounds from very active adsorbents is in general better by extraction than by thermal desorption. Thus for liquid-liquid extraction very efficient adsorbents, e.g., active charcoal, or adsorbents of limited thermal stability, such as some of the XAD resins, are also suitable. Other advantages of extraction are that the sample obtained can be analysed with the usual chromatographic instrumentation without modification, including essentially all established relevant sample preparation techniques (e.g., solvent evaporation, derivatization). Extraction of solid samples for trace analysis is a technique that is widely used in chemical laboratories and thus instrumentation and experience are readily available. As the volume of the extract is generally larger than the volume which is used for a single chromatographic analysis, it is possible to analyse the same sample with different instruments or under different conditions. The repetition of measurements also presents no problem. The capacity of chromatographic columns, especially capillary columns, is limited but currently available injection techniques allow the separation of substantial sorbent volumes. Thus the injection of a major fraction of the total sample is in principle possible. However, it should be remembered that splitless injection techniques may present some problems owing to discrimination of heavier or thermaly labile components of the sample $[69,70]$. Also, for components with boiling points comparable to that of the solvent, splitless injection techniques often lack reproducibility. Further, liquid-liquid extraction of the adsorbed samples not only requires more handling but also increases the risk of sample contamination and blank values, e.g., from the solvents used.

Numerous procedures for adsorptive sampling and liquid-liquid extraction have been published and combinations of various adsorbents and different extraction procedures allow the technique to be adapted to a wide range of analytical problems [71-77, and references cited therein]. Frequently used adsorbents are active charcoal, por- ous silica and alumina, molecular sieves and several organic porous polymers (Tenax, XAD resins, Porapak, etc.). The adsorbents are extracted with low-boiling solvents such as carbon disulphide, dichloromethane, benzene or pentane, mostly with Soxhlet-type extraction procedures. The final volume of solvent is in general a few to several tens of $\mathrm{ml}$, but more elaborate procedures which allow concentration of the analytes in a few $\mu 1$ have also been described [78].

The adsorption traps contain on average between several hundred $\mathrm{mg}$ to several $\mathrm{g}$ of adsorbent, often more than usual for thermal desorption. Also, the flow-rates and the total sample volumes are larger, several $\mathrm{dm}^{3} \mathrm{~min}^{-1}$, and total volumes of several hundred $\mathrm{dm}^{3}$ are not unusual and occasionally volumes in the range of several $\mathrm{m}^{3}$ are sampled, e.g. for measurements of pollu$\operatorname{tant}$ levels of $\mathrm{ng} \mathrm{m}^{-3}$ or less [76]. For measurements of average or low pollution levels, rigorous precleaning of the adsorbent is of prime importance. Soxhlet extraction with water, methanol and solvents of low polarity is used in addition to thermal pretreatment. As compounds of higher volatility, with vapour pressures comparable to that of the solvent used, can be partly lost during the extraction procedure, the most widespread applications are measurements of low-boiling substances such as polychlonnated biphenyls, dibenzodioxins, dibenzofurans and polyaromatic hydrocarbons, but hydrocarbons, aldehydes and halogenated hydrocarbons have also been analysed.

The problems of artefact formation or losses during sampling or storage as result of reactions between reactive atmospheric components and the adsorbent or the sampled compounds are essentially the same as for thermal desorption. However, owing to the generally much larger sample volumes, artefacts or blanks which are independent of the sampling time and volume are less important, but the higher loading of the adsorbent with the analytes and other atmospheric reactive components increases the risk of sample degradation by reactions involving atmospheric trace constituents.

\section{Passive sampling}

Instead of passing the air sample through the 
TABLE 4

Examples of absorptive and chemisorptıve sampling of organic volatiles in air

\begin{tabular}{|c|c|c|c|c|c|c|}
\hline Sampling device & $\begin{array}{l}\text { Samplung } \\
\text { ume (mun) }\end{array}$ & $\begin{array}{l}\text { Sampled } \\
\text { volume } \\
\left(\mathrm{dm}^{3}\right)(\mathrm{STP})\end{array}$ & Analysed compounds & $\begin{array}{l}\text { Concentration } \\
\text { range }\left(\mu \mathrm{g} \mathrm{m}^{-3}\right)\end{array}$ & Comments & Ref. \\
\hline $\begin{array}{l}\text { Impinger with } \\
\text { 2,4-dinitrophenyl- } \\
\text { hydrazine solution }\end{array}$ & 60 & 60 & Some aldehydes & $05-100$ & $\begin{array}{l}\text { Denvative analyzed } \\
\text { by LC }\end{array}$ & 82,91 \\
\hline $\begin{array}{l}\text { Rotating glass tube } \\
\text { with Raschig nngs, } \\
\text { 2,4-dinitrophenyl- } \\
\text { hydrazine solution }\end{array}$ & $30-60$ & $1000-2000$ & Formaldehyde & $01-10$ & As above & $79-81$ \\
\hline $\begin{array}{l}\text { Condensation samp- } \\
\text { ling below dew } \\
\text { point of atr }\end{array}$ & -120 & $1000-2000$ & $\begin{array}{l}\text { Light alcohols, } \\
\text { carbonyls, } \\
\text { acetonitrile }\end{array}$ & $0.2-40$ & $\begin{array}{l}\text { Sampling efficiency } \\
\text { depends strongly on } \\
\text { Henry's constants }\end{array}$ & 101 \\
\hline $\begin{array}{l}\text { Cartridges with } \\
\text { 2,4-dinitrophenyl- } \\
\text { hydrazine on solid sorbents }\end{array}$ & $4-60$ & $2-100$ & Aldehydes, ketones & $05-1000$ & $\begin{array}{l}\text { Analysis of denva- } \\
\text { tove by } L C \text { and } G C\end{array}$ & $87,88,90$ \\
\hline $\begin{array}{l}\text { Glass-fibre filters } \\
\text { with 2,4-dinitrophenyl- } \\
\text { hydrazine impregnation }\end{array}$ & $30-60$ & $30-60$ & Formaldehyde & $1-20$ & $\begin{array}{l}\text { Sampling efficiency } \\
\text { depends on relatıve } \\
\text { humidity }\end{array}$ & 89 \\
\hline $\begin{array}{l}\text { Mist chamber with } \\
\text { aqueous alkalıne } \\
\text { solution }\end{array}$ & $30-120$ & $150-1000$ & Carboxylic acids & $05-50$ & $\begin{array}{l}\text { Analysis by ion } \\
\text { chromatography }\end{array}$ & 95 \\
\hline $\begin{array}{l}\text { Denuders coated } \\
\text { with sodium hydroxıde }\end{array}$ & $30-120$ & $300-1000$ & Carboxylic acids & $05-100$ & $\begin{array}{l}\text { Analysis by ion } \\
\text { chromatography }\end{array}$ & 99,100 \\
\hline
\end{tabular}


sorbent, it is also possible to bring the adsorbent into contact with air and collect an amount of sample which is determined by the diffusion of the analyte through the air to the adsorbent bed. In order to allow quantitative determination of the air composition from the amount of analyte adsorbed, the exposure has to be done in a way which ensures that a defined, diffusion-limited step controls the rate of uptake from the atmosphere. An overview over several types of passive samplers and their performance was given by Brown et al. [79]. Essentially all applications of passive samplers are in the field of indoor pollution, industrial hygiene and similar monitoring tasks for fairly high levels of pollution $\left(\mathrm{mg} \mathrm{m}^{-3}\right.$ ). The sampling rate of passive samplers is low owing to the rate-determining slow diffusion step. Consequently, at low atmospheric concentrations the amount of sample is too small for analyses or the exposure periods are extremely long. This problem seems to outweigh the advantages of passive sampling such as simplicity of use, low costs and no requirement for electric power durng sampling. Apart from a few outdoor measurements [e.g., $80,81]$ there have been essentially no measurements of organic pollutants at the $\mu \mathrm{g} \mathrm{m}^{-3}$ level or below by passive sampling techniques.

\section{ABSORPTIVE SAMPLING AND SAMPLING ON IM- PREGNATED SURFACES}

This section discusses not only sampling processes that use purely physical absorption in a liquid phase, but also those techniques which combine the solution step with a chemical reaction in the solution. In general, the techniques used to bring the liquid into contact with air are independent of the composition of the solution or any chemical reaction following the solution process. This paper does not deal with chemical derivatization reactions which are applied after sampling as these procedures are essentially identical with methods that are widely used for the analysis of solutions. It should be noted that liquid organic phases as purely physical absorption media are nowadays only rarely used. In principle, organic liquids on a solid support can be used in the same way as solid sorbents. However, for a number of practical reasons, e.g., evaporative losses during sampling and miscibility with the solvents used to recover the sampled substances, they are inferior to organic porous polymers.

It is therefore not surprising, that absorptive sampling is most widely used for polar organic substances with functional groups that cause a high solubility in water or polar organic solvents or that allow a sufficiently fast derivatization reaction in the solution to shift the gas-solvent equilibrium sufficiently far to the side of the condensed phase. Most of the successful applications are for aldehydes and ketones [81-94] or carboxylic acids [95-102]. Also applications of sampling of light alcohols or nitriles have been published $[103,104]$. As basically the same kinds of reactions and reagents are also used for sampling on impregnated surfaces (e.g., filters or adsorbent cartridges treated with a reagent) and the subsequent analytical measuring techniques are in general identical (ion chromatography, LC, occassionaly GC), these sampling procedures are included here.

Some examples of absorptive or chemisorptive sample collection of organic trace constituents in the atmosphere are listed in Table 4. For organic acids a considerable fraction of the total atmospheric concentration can be in the particle phase. If a differentiation between gas and particulate phases is required, the aerosol particles have to be separated from the gas phase prior to sampling, e.g., by passing the air sample through a Teflon filter. Impinger or washing flask types of samplers are probably the most readily available, cheapest and easiest to use devices for sampling in solution. However, they usually allow only moderate sampling rates of ca. $1 \mathrm{dm}^{3} \mathrm{~min}^{-1}$ and therefore long sampling periods are needed for measurements at low concentration levels. Higher flow-rates, and consequently shorter sampling times or better detection limits, can be achieved with more sophisticated samplers such as rotated tubes packed with Raschig rings or mist (spray) chambers [81-83,97]. Also, the condensation of water on a plate kept below the dew point of the sampled air allows sampling from substantial volumes, but this technique is not only elaborated but also 
limited to compounds with high water solubility, as it does not allow the sampling efficiency to be improved by derivatizing the dissolved organic compounds in the liquid phase [103,104].

For measurements of aldehydes and ketones 2,4-dinitrophenylhydrazine is the most widely used reagent, but other substances, e.g., 5,5-dimethylcyclohexane-1,3-dione or cyclohexane-1,3-dione, which allow very sensitive fluorimetric detection in combination with LC, can also be used $[105,106]$. Carbonyl compounds are now generally sampled on impregnated solid sorbents in cartridges which are subsequently extracted with organic solvents. Commercial cartridges with treated or untreated porous silica or alumina are widely used. They are impregnated with solutions of the same types of reagents which are used for sampling in solutions. These sampling tubes allow substantial flow-rates of several $\mathrm{dm}^{3} \min ^{-1}$ without reducing the sampling efficiency. Glassfibre filters impregnated with 2,4-dinitrophenylhydrazine have also been used for both active and passive sampling [91]. However, the maximum flow-rate is limited to $1 \mathrm{dm}^{3} \mathrm{~min}^{-1}$ and the maximum sample volume to $60 \mathrm{dm}^{3}$.

Much higher sample volumes and flow-rates can be applied for the sampling of gaseous carboxylic acids from air if filters impregnated with sodium or potassium hydroxide or carbonate are used. However, intercomparison experiments [107] have shown that substantial artefacts for formic acid can be caused by sampling on alkaline filters. Such artefacts are not observed with denuder or mist chamber sampling [108]. Another advantage of denuder-type samplers is the separation between the gas and particle phases without the use of filters which might cause further interferences. However, denuder systems are more expensive than filters and more elaborate to use.

\section{Conclusions}

There are a substantial number of different sampling procedures for organic volatiles in the atmosphere at moderate or low pollution levels. In general, these various techniques have been tested and applied with more or less specific monitoring tasks, e.g., a few defined compounds or certain levels of pollution. There are only a few sampling techniques that have been applied to a broader range of compounds.

Whole-air sampling and subsequent analysis by GC, often combined with a cryogenic preconcentration step, have been widely and successfully used for measurements of low and medium molecular weight compounds of moderate or low polarity such as hydrocarbons and halocarbons. The key to precise and accurate results is the sample container and to some extent also the collection procedure. Stainless-steel containers with metal bellows valves allow collection and storage for a reasonable time without significant changes in the concentrations of a substantial number of atmospheric trace gases even at concentration levels of $\mu \mathrm{g} \mathrm{m}^{-3}$ and less. Sampling in evacuated canısters at ambient pressure is possibly the simplest collection procedure. The amount of sample is limited, but in general sufficient for measurements of trace constituents at the $0.1-0.01 \mu \mathrm{g} \mathrm{m}^{-3}$ level if an ionization detection method (electron-capture, flame ionization, photoionization detection) is used. Larger air volumes can be collected if the sample is pressurized, either with metal bellows pumps or cyrogenically. However, this causes some additional problems of possible sample deterioration and more elaborate instrumentation in the field is needed. Unfortunately, these sampling flasks are expensive to built and the necessary techniques are not easily available. This is probably the only reason why other types of sample containers such as glass flasks with PTFE stopcocks or aluminized plastic bags are still used, although they can cause contamination effects in the range of several $\mu \mathrm{g} \mathrm{m}^{-3}$.

Another widely applicable collection technique is sampling on non-polar porous organic adsorbents such as Tenax. Combined with thermal desorption and cryotrapping, this technique is suitable for the determination of organic volatiles at concentrations as low as $0.01 \mu \mathrm{g} \mathrm{m}^{-3}$ with a precision of 10-20\%. Portable and batterypowered sampling devices are available and field sampling is relatively simple. This technique is mainly applicable to compounds with boiling points in the range $350-600 \mathrm{~K}$, and therefore is not so much a substitute but rather a supplement 
to grab sampling. The main limitations arise from artefacts or losses due to chemical reactions during sampling. As those problems are not easily investigated by laboratory tests, only a small number of the various applications of this type of sampling have been checked for such interferences. These two methods are generally combined with GC analyses and need additional equipment to be interfaced with commercial, standard gas chromatographs.

Sampling by absorption, adsorption or chemisorption in combination with liquid-liquid extraction results in a sample that can be analysed by essentially all procedures for the measurement of trace compounds in solvents. Thus, the relatively low cost of the additionally needed sampling equipment and the (at least theoretical) possiblity of determining substances which are present in the atmosphere at levels of $\mathrm{ng} \mathrm{m}^{-3}$ or even less are probably the explanations for an overwhelming number of different applications. However, the large volumes of air drawn through the sampling trap increase the problem of sample deterioration due to reactions during collection. Testing a sampling technique which uses large volumes of air (often several $\mathrm{m}^{3}$ ) is not trivial and it is therefore not surprising that the knowledge of the possible effects of chemical reactions during sampling induced by reactive trace constituents of the atmosphere is still very limited.

In conclusion, there is a reasonable range of procedures for the determination of organic volatiles in the atmosphere which are suitable for measurements at concentration levels down to a few $\mu \mathrm{g} \mathrm{m}^{-3}$ to a fraction of a $\mu \mathrm{g} \mathrm{m}^{-3}$. However, there is definitly a lack of testing and validating such techniques under real atmospheric conditions.

\section{REFERENCES}

1 B Bonsang and G. Lambert, J Atmos. Chem., 2 (1985) 257.

2 J.P Greenberg and P.R. Z1mmerman, J. Geophys. Res, 89 (1984) 4767

3 K J.W Tille, M Savelsberg and K. Bächmann, Atmos Environ., 19 (1985) 1751.

4 J. Rudolph and A Khedim, Int. J. Environ Anal. Chem., 30 (1985) 265
5 J. Rudolph, F.J. Johnen and A. Khedım, Int. J. Environ Anal. Chem., 27 (1986) 97

6 B Lamb, H Westberg and G. Allwine, Atmos Envron., 20 (1986) 1.

7 D.L de Lorey, D.R. Cronn and J.C. Farmer, Atmos Environ, 22 (1988) 1481

8 J. Colbeck and R.M. Harnson, Atmos. Environ., 19 (1985) 1899

9 A P. Altshuller, W.A. Lonneman, F.D. Sutterfield and S.L. Kopczynsk1, Environ. Sc1. Technol., 10 (1976) 1009.

10 R R Arnts and S.A. Meeks, Atmos. Environ., 9 (1981) 1643

$11 \mathrm{~K}$ Sexton and H. Westberg, Atmos. Environ., 18 (1984) 1125.

12 W.A Lonneman, S L. Kopczynska, P.E Darley and F.D Sutterfield, Environ. Sci. Technol , 8 (1974) 229.

13 W.A. Lonneman, R L. Sella and J.J Bufalın, Envuron. Sc1. Technol., 12 (1978) 459

14 D.R. Cronn, R.A. Rasmussen, E. Robınson and D.E Harsch, J. Geophys. Res., 82 (1977) 5935

15 J. Uno, S. Wakamatsu, R A. Wadden, S. Konno and H. Koshio, Atmos. Environ., 19 (1985) 1283.

16 R A. Rasmussen, M.A. Khall and R J. Fox, Geophys Res. Lett, 10 (1983) 144.

17 W. Nutmagul and D.R Cronn, J Atmos. Chem, 2 (1985) 415

18 J. Rudolph and D.H. Ehhalt, J Geophys Res., 86 (1981) 11.959

19 J. Rudolph, J. Geophys Res., 93 (1988) 8367

20 R.L Seila, W.A. Lonneman and S.A. Meeks, J. Environ. Sci Health Environ. Sc1. Eng., A11 (1976) 121.

21 E.R Stephens and F.R Burleson, J. Aur Pollut. Control Assoc., 19 (1969) 929.

$22 \mathrm{~W}$ Schneider and J.Ch Frohne, Staub-Reinhalt. Luft, 35 (1975) 275.

23 L A. Cavanagh, C.F Schadt and E.R Robinson, Environ Sci. Technol., 3 (1969) 251.

24 J V Behar, L Zafonte, R.E. Cameron and F A Morell, Antarctic J., 7 (1972) 94

25 G.P Ayers and R W Gillet, J. Atmos. Chem., 7 (1988) 177.

26 P. Leinster, R Perry and R.J. Young, Talanta, 24 (1977) 205

27 A.C. Alken, C.C. Gallagher, CW Spicer and M.W Holdren, J. Geophys. Res, 92 (1987) 3135

28 D.R. Blake and F S. Rowland, Nature (London), 321 (1986) 231

29 J.P. Greenberg, P R. Zimmerman, L. Heidt and W. Pollock, J. Geophys. Res, 89 (1984) 1350.

30 R N Grenda and H.W Goldstein, J. Geophys. Res, 82 (1977) 5923

31 J Rudolph, D H Ehhalt, A Khedım and C. Jebson, J Chromatogr., 217 (1981) 301

32 D Cronn and E. Robinson, Geophys Res Lett., 6 (1979) 641.

33 D H. Ehhalt, Rev Geophys. Space Phys, 16 (1978) 217

34 E. Robinson, R.A Rasmussen, H.H Westberg and M W. Holdren, J Geophys Res., 78 (1973) 5345.

35 P Övrum, Am. Ind. Hyg Assoc J., 47 (1986) 650 
36 K. Figge, A.M. Domróse, W. Rabel and W. Zerhau, Fresenus' Z. Anal. Chem., 327 (1987) 279.

37 Th. Class and K. Ballschmiter, Fresenuus' Z. Anal Chem., 325 (1986) 1.

38 Th Class and K. Ballschmiter, J. Atmos. Chem., 6 (1988) 35

39 Th. Class and $K$ Ballschmiter, Fresenius' $Z$ Anal. Chem., 327 (1987) 198.

40 J M. Roberts, F.C Fehsenfeld, S.C Liu, M.J. Bollinger, C. Hahn, D.L. Albritton and R E Sievers, Atmos. Environ., 18 (1984) 2421

41 J M. Roberts, F.C. Fehsenfeld, D.L. Albritton and R.E. Sievers, J. Geophys. Res., 88 (1983) 10.667.

42 J.W Russell, Environ. Sc1 Technol., 13 (1975) 1175.

43 L. Wenunch, $T$ Welsch and W. Engewald, J Chromatogr., 241 (1982) 49

44 G. Holzer, H. Schanfield, A Zlatkıs, W. Bertsch, P. Juarez and H. Mayfield, J Chromatogr., 142 (1977) 755.

45 B.V. Joffe, V A Isidorov and I.G Zenkevich, J. Chromatogr , 142 (1977) 787.

46 V.A. Isidorov, I G. Zenkevich and B V. Joffe, Atmos Environ., 19 (1985) 1.

47 P. Neulıng, R. Neeb, R. Exchmann and C Junge, Fresenus' Z Anal Chem., 302 (1980) 375

48 T Noy, $P$ Fabian, $R$ Borchers, F Janssen, C Cramers and J. Rujks, J Chromatogr , 393 (1987) 343

49 A.J. Netravalkar and A.M. Mohan Rao, Chromatographia, 22 (1986) 183.

50 E. Neuber, H W Georgu and J. Müller, Staub-Reınhalt Luft, 41 (1981) 91

51 R.S. Hutte, E.J. Willams, J. Staehelin, S.B Hawthorne, R.M Barkeley and RE. Sievers, J Chromatogr, 302 (1984) 173.

52 K. Figge, W. Rabel and A Wieck, Fresenus' Z. Anal Chem., 327 (1987) 261

53 J. Rudolph, F J. Johnen, A Khedım and G. Pilwat, Int J. Environ Anal. Chem., 38 (1990) 143

54 J.F Pankow and T J Kristensen, Anal. Chem, 55 (1984) 2187

55 L D. Ogle, R C Hall, W.L Crow, A.E. Jones and J.P Gise, in L H. Keith (Ed.), Identification and Analysis of Organic Pollutants in Air, Butterworth, Boston, 1984, p. 171

56 J M. Roberts, F.C Fehsenfeld, D L. Albritton and R.E Sievers, in L.H Keith (Ed), Identification and Analysis of Organic Pollutants in Air, Butterworth, Boston, 1984, p 371

57 E. Pellizan, B. Demıan and K Krost, Anal Chem, 56 (1984) 793

58 J.F. Walling, J.E Bumgarner, D J Driscoll, C.M. Morris, A E. Riley and L.H Wright, Atmos. Environ, 20 (1986) 51.

59 P R. Evans and S N Horstmann, Am Ind Hyg. Assoc J, 42 (1981) 403

60 D.P. Rounbehler, J N Relsch, J.R. Coombe and D.H. Fine, Anal Chem, 52 (1980) 273.

61 J.E. Bunch and E D Pellızzan, J. Chromatogr., 186 (1979) 811
62 W. Hertle and M.G. Neumann, J Chromatogr, 60 (1971) 319.

63 M.G Neumann and S T Morales, J. Chromatogr, 74 (1972) 332

64 M B. Neher and P.W Jones, Anal Chem., 49 (1977) 512.

65 J.M Trowell, J. Chromatogr. Sc1., 9 (1971) 253.

66 C.H. Lochmuller, M.W Ewalt and E.C. Jenson, Int J Environ Anal Chem., 8 (1980) 37.

67 J.F. Walling, Atmos Environ, 18 (1984) 855

68 Yu.S Dnugov and V.G. Berezhun, Russ Chem. Rev, 55 (1986) 546.

69 K. Grob and K Grob, Jr., J. High Resolut. Chromatogr Chromatogr Commun., 1 (1978) 57.

$70 \mathrm{~K}$. Grob and G Grob, J High Resolut Chromatogr. Chromatogr. Commun, 2 (1979) 109.

71 G A. Junk and J.J. Ruchard, in L.H Keith (Ed), Identıfication and Analysis of Organc Pollutants in Air, Butterworth, Boston, 1984, p. 61

72 P. Leinster, R. Perry and R J Young, Talanta, 24 (1977) 205.

73 S.J C. Petrowskı, J.R Kaplan and B.R T Sımoneıt, J Air Pollut Control Assoc., 30 (1980) 1098

74 R.B Jacko and M L Holcomb, J Aur Pollut Control Assoc, 31 (1984) 156.

75 E. Atlas, Nature (London), 331 (1988) 426.

76 F. Bouchertall and J C. Dunker, Anal. Chum. Acta, 185 (1986) 369

77 C.S Davis, P. Fabian and R. Otson, J Aur Pollut. Control Assoc., 37 (1987) 1397.

78 E.L Atlas and K.F Sullivan, Anal Chem., 57 (1985) 2417

79 R.H Brown, PC Cox, C.J. Purnell, N.G. West and M D. Wright, in L H Keith (Ed.), Identification and Analysis of Organic Pollutants in Air, Butterworth, Boston, 1984, pp 37.

80 J.D Mullik, R.G. Leavis and W A. McClenny, Anal. Chem., 61 (1989) 187.

81 D C Lowe and U Schmidt, J Geophys. Res, 88 (1983) 10844

82 D C Lowe, U. Schmidt and D.H Ehhalt, Geophys Res Lett., 7 (1980) 825.

83 D C Lowe, U. Schmidt and H W Nürnberg, Environ. Scı Technol , 15 (1981) 819.

84 D. Grosjean, Environ. Sc1. Technol., 16 (1982) 254.

85 P. Schalam, R. Newbold and L A Hull, Atmos Environ, 19 (1985) 623

86 R. Kuntz, W Lonneman, G Name and L A Hull, Anal Lett., 13 (1980) 1409.

$87 \mathrm{G}$ Anderson and K. Anderson, Chemosphere, 10 (1979) 823

88 R K Beasley, C.E. Hoffmann, M.L. Rueppel and J M. Worley, Anal. Chem, 52 (1980) 1110

89 K Kuwata, M Kebon, H. Yamasakı, Y Kuge and Y. Kıso, Anal Chem, 55 (1983) 2013

90 J P. Guenier, P. Simon, J Delcourt, M.F. Didierjean, L Lefevre and J. Muller, Chromatographa, 18 (1984) 137

91 J.-O. Levin, K Andersson, R Lindahl and C A Nilsson, Anal. Chem, 57 (1986) 1032. 
92 F Lipari and S J Swarin, Envron. Sc1. Technol., 19 (1985) 70

93 D. Grosjean and K Fung, Anal. Chem, 54 (1982) 1221.

94 R L Tanner, A.H. Miguel, J.B. de Andrade, J.S. Gaffney and G.E. Streit, Environ Sci. Technol., 22 (1988) 1026.

95 K. Kawamura, L-L. Ny and J.R Kaplan, Environ. Sci. Technol., 19 (1985) 1082.

96 G.A. Dawson and J.C Farmer, J. Geophys Res., 93 (1988) 1988.

97 W R. Cofer, III, V.G. Collıns and R W Talbot, Environ Sc1 Technol., 19 (1985) 557

98 M.O. Andreae, R.W. Talbot, T.W. Andreae and R L Harriss, J Geophys. Res., 93 (1988) 1616.

99 D L Hayner, in J D Nulwik and E. Sawıckı (Eds.), Ion Chromatographic Analysis of Environmental Pollutants, Vol. 2, Butterworth, Stoneham, MA, 1979, p. 157

100 W.C. Keene and J.N. Galloway, J. Geophys. Res, 91 (1986) 14466.

101 H. Puxbaum, C. Rosenberg, M. Gregon, C Lausersdorfer, E. Ober and W. Winıwarter, Atmos. Environ., 22 (1988) 2841.
102 C Rosenberg, W. Winiwarter, M. Gregon, G. Pech, V Casensky and H. Puxbaum, Fresenus' $Z$ Anal Chem., 331 (1988) 1.

103 J.R. Snider and G A Dawson, J. Geophys. Res., 90 (1985) 3797.

104 J C Farmer and G.A Dawson, J Geophys Res., 89 (1984) 8931.

$105 \mathrm{~K}$ Mopper, W.L Stahovec and L Johnson, J. Chromatogr., 256 (1983) 243.

106 W L Stahovec and K. Mopper, J Chromatogr, 298 (1984) 399.

107 W C Keene, R.W Talbot, M O. Andreae, K. Beecher, H Berresherm, M. Castro, J C. Farmer, J.N. Galloway, M R Hoffmann, S-M. L1, J.R Maben, J.W. Munger, R B Norton, A.P. Pszenny, H. Puxbaum, H. Westberg and W Winiwarter, J Geophys. Res., 94 (1989) 6457.

108 R.W. Talbot, K M. Stein, R C Harriss and W.R Cofer, III, J. Geophys. Res, 93 (1988) 1638. 